\title{
A PRODUÇÃO DO FRACASSO ESCOLAR:A TRAJETÓRIA DE UM CLÁSSICO
}

\author{
José Sérgio F. de Carvalho
}

Resumo: Publicado pela primeira vez há mais de duas décadas, $A$ Produção do Fracasso Escolar, de Maria Helena Souza Patto, segue sendo uma obra de referência para pesquisadores em educação, gestores de sistemas e professores. Como explicar sua longevidade e fecundidade em um campo tão marcado pela rápida obsolescência de autores, teorias e perspectivas educacionais? No presente artigo apresentamos duas hipóteses complementares para essa sólida trajetória de sua obra. A primeira delas diz respeito ao potencial elucidativo de seu estudo que, recusando o jargão e os procedimentos cientificistas que apagam a concretude do real em favor de uma linguagem matematizada e padronizadora, apresenta um quadro significativo e complexo do cotidiano de uma instituição escolar e dos agentes nela envolvidos. Em suas análises emerge a singularidade desses agentes, tantas vezes obscurecidas por rótulos e fórmulas abstratas. Por outro lado, em sua pesquisa a peculiaridade do cotidiano de uma instituição não se desliga dos condicionantes históricos de natureza política e social que têm marcado as concepções e práticas educativas em nossa sociedade.

Palavras-chave: Fracasso escolar. Psicologia educacional. Professores. Escolas.

Pesquisadores e profissionais da educação que têm acompanhado a produção teórica do campo nas últimas décadas assistem - alguns perplexos, outros com ingênua alegria ou esperança - à rápida aparição e obsolescência de toda sorte de novidades teóricas e discursivas que se alternam nos modismos pedagógicos num 
ritmo avassalador. Teorias, prescrições, discursos apocalípticos ou redentores se sucedem no volátil "mercado de ideias" em que se transformou o campo da educação; a cada estação difundem um 'novo' jargão pedagógico cuja anemia semântica é tão incapaz de alterar práticas como de oferecer qualquer inteligibilidade à concretude dos fenômenos que marcam a cultura das instituições escolares.

Num panorama desolador como esse a trajetória da obra A Produção do Fracasso Escolar, de Maria Helena Souza Patto, é rara e surpreendente. Resultado de um estudo realizado na década de 1980 e publicado pela primeira vez em 1990, a obra teve quatro reimpressões e sua segunda edição, publicada em 2000, já conta com a primeira reimpressão. Em 1995 mereceu o prêmio de livro de maior relevância para a área, concedido pela APEOESP. Aparece com mais de 700 citações no Google Acadêmico.É referência permanente em concursos públicos para o magistério; tornou-se bibliografia recorrente de cursos de graduação e pós-graduação e tem sido um constante elemento desencadeador de novos estudos e pesquisas; dentre elas uma que procura retraçar os destinos de Ângela, Augusto, Nailton e Humberto, quatro alunos da escola pública cujas trajetórias de reprovação foram descritas com solidariedade, compreensão e indignação em um de seus capítulos finais.' Como explicar a longevidade, a fecundidade e - ainda mais surpreendente - a popularidade de uma obra acadêmica tão densa?

Uma hipótese bastante plausível é a de que A Produção do Fracasso Escolar parece ter se tornado um "clássico" nas áreas de educação e psicologia e, como nos lembra Calvino (1993),"um clássico é um livro que nunca terminou de dizer aquilo que tinha para dizer e que por isso persiste... mesmo onde predomina a atualidade mais incompreensível" (pp. 11-15). Mas afirmar seu progressivo reconhecimento como um 'clássico' antes elide o problema do que a ele dá uma resposta satisfatória; afinal, a questão simplesmente se desloca: por que a obra tem caminhado para se configurar como um 'clássico'? Onde reside sua força para romper com essa tendência dominante de diluir o impacto de pesquisas acadêmicas reduzindo-as a meros procedimentos para a obtenção de títulos e ascensão na carreira universitária? Como pode perdurar sua capacidade iluminadora em meio a um contexto tão marcadamente cambiante, como o que caracteriza as políticas de educação nos últimos vinte anos? Não há respostas inequívocas para esses questionamentos, mas sempre é possí-

1 Trata-se da dissertação de mestrado Histórias de (re)provação escolar (Amaral, 2010), elaborada sob a supervisão da Professora. Dra. Denise Trento (FE-USP) que, na década de oitenta, participou da equipe de trabalho da Professora Maria Helena Patto para a elaboração da pesquisa que resultou na obra $A$ produção do fracasso escolar. 
vel arriscar algumas hipóteses acerca das razões desse impacto amplo e persistente que tem caracterizado a sua recepção.

\section{A ruptura teórico-metodológica}

No prefácio à sua segunda edição, a professora Jerusa Vieira Gomes ressalta que a obra de Patto representou uma ruptura teórico-metodológica nos estudos sobre o "fracasso escolar". Tratava-se, a seu ver, de um novo marco na compreensão dos processos psicossociais envolvidos nas práticas sociais e escolares responsáveis pela produção de "reprovados", "fracassados" e por toda sorte de estigmas que afirmam a incompatibilidade de certas crianças das classes populares para com a aprendizagem e a cultura escolar. Um dos fatores responsáveis por essa 'ruptura' com modelos de pesquisa precedentes é a recusa de Souza Patto em isolar as raízes escolares do "fracasso" de seus condicionantes históricos e sociais ao perscrutar as práticas escolares - discursivas e não discursivas - de professores, coordenadores e diretores e ao analisar a produção social de uma visão de mundo que informa e legitima tais práticas.

A primeira parte do livro apresenta-nos, então, uma rigorosa arqueologia das explicações, no pensamento pedagógico brasileiro, para o "fracasso" escolar de crianças das classes populares. $O$ tema é examinado desde suas manifestações iniciais, fundadas num recorte racial que afirmava a inferioridade constitucional de amplos segmentos da população brasileira, até as relativamente recentes teses da diferença - e inferioridade - cultural subjacentes às chamadas "teorias da carência cultural". Nesse esforço genealógico Patto (2000) não poupa críticas ao papel de uma "psicologia que desde seu nascimento baseia-se numa definição conservadora de ajustamento e de normalidade e que centra suas investigações no que ocorre no indivíduo ou nas relações interpessoais, entendidos como entidades a-históricas" (p. 67). Nessa perspectiva o "fracasso escolar" tende a ser concebido como resultante de "distúrbios de personalidade" ou de obstáculos - sejam eles orgânicos, afetivos, familiares ou culturais - que afetam o indivíduo isoladamente considerado; as relações entre professores e alunos, por sua vez, tendem a ser vistas em abstração do entorno institucional em que ocorrem e dos condicionantes políticos e ideológicos que sobre elas incidem.

Mas o caráter marcante e inovador da obra não reside na enunciação genérica desses condicionantes e dos vínculos entre uma estrutura social excludente e preconceituosa e a "produção do fracasso escolar."Ao contrário, a autora se distancia dessa modalidade recorrente de estudo acadêmico que se limita a "aplicar" à realidade brasileira teses prontas, transpondo conceitos e hipóteses cuja aceitação in toto parece dispensar o pesquisador do laborioso contato com a realidade empírica e de 
sua paciente reconstrução numa rede conceitual capaz de desvelá-la em sua concretude histórica. $O$ trabalho de Patto, ao mergulhar no cotidiano de uma escola pública da periferia de uma metrópole, faz emergir a peculiaridade do diálogo de uma cultura escolar - objetivada em mentalidades, discursos, atitudes, regulamentações e procedimentos disciplinares, avaliativos etc. - com uma totalidade social específica. Ao optar pela captação dessa cotidianidade das relações numa instituição escolar e em seu entorno social, Patto faz emergir as esperanças, os preconceitos, os dramas e sonhos de professores, alunos, pais, coordenadores pedagógicos e diretores que nas páginas de sua obra não são tratados como "números","estruturas" ou "objetos", mas como sujeitos cuja voz, os gestos, os desenhos nos guiam por entre os labirintos obscuros do cotidiano escolar.

Compare-se, a fim de ilustrar a ruptura com o paradigma então corrente, as páginas em que Ângela é descrita pela pesquisadora com as observações que constam de seu 'laudo psicológico', feito por um profissional da própria equipe da Prefeitura no início de 1985 e transcrito no livro de Souza Patto. Esse laudo nos informa que, no que concerne aos resultados intelectuais, Ângela obteve $Q I V=66 ; Q I E=64 ; Q I T=62$, que seu nível de inteligência situa-se "abaixo da faixa média de normalidade e que ela apresentou alguma dificuldade para análise e síntese e dificuldade em perceber minúcias, detalhes em atividades que exijam rapidez e precisão" (Patto, 2000,p.364). Ao elaborar uma"descrição"pseudocientífica, que recorre a um jargão semiespecializado a serviço da estigmatização escolar e social, ele produz um paradoxo: aparentemente trata-se de uma descrição precisa e confiável porque "científica" (o QIV é exatamente 66; nem um ponto a mais, nenhum a menos!), mas o fato é que ao lê-lo não nos tornamos capazes de compreender quem é Ângela e quais são suas dificuldades concretas no processo de escolarização. O que significa, por exemplo, dizer que ela tem dificuldade em perceber minúcias, detalhes em atividades que exijam rapidez e precisão? Em quantos de nós esse diagnóstico não seria igualmente válido em relação a certas atividades, como dirigir um automóvel ou revisar um texto, mas não em relação a outras, como criar um sofisticado prato culinário?

Ainda mais importante é o fato de que mesmo a leitura do laudo em sua íntegra não nos capacita a compreender a questão central do ponto de vista escolar: quais as alegadas razões cognitivas que justificariam suas reprovações? O laudo expedido supostamente nos informaria sobre as dificuldades afetivas de Ângela, seus medos e inseguranças, mas não nos informa acerca do que ela sabe ou não fazer no campo dos saberes típicos de um currículo escolar, nem quais seriam suas alegadas dificuldades de aprendizagem nesse âmbito específico, tampouco o que foi feito no sentido de levá-la à superação dos problemas detectados. Não obstante seu caráter vago, esse tipo de diagnóstico tem sido um podero- 
so elemento no processo de legitimação do suposto caráter individual do 'fracasso escolar' e no ocultamento de suas raízes sociais e escolares. Ainda mais grave, ele acaba por se constituir em fator condicionante desse mesmo fracasso, na medida em que concorre para a realização daquilo que profetiza como fado inexorável.

Esse é o caso, por exemplo, de M., menino de 12 anos de idade, estigmatizado como portador de algum tipo de "retardo mental" que explicaria, a partir de fatores exclusivamente exteriores às práticas escolares, seu baixíssimo rendimento escolar. Em face de uma prova considerada pela professora como "péssima", a pesquisadora constata que há questões respondidas corretamente que não são computadas e respostas corretas que são consideradas erradas. Apontado o equívoco, a professora justifica seu lapso como fruto de uma distração. Mas a recorrência de episódios dessa natureza parece sugerir que a certeza, por parte da professora,"de que ele é retardado mental e não tem nenhuma condição de passar de ano é confirmada ao primeiro erro e contamina toda a correção da prova" (Patto, 2000, p. 312).

Do ponto de vista das práticas escolares, mais do que descrever um estado prévio ou constitutivo do sujeito, o'diagnóstico' - seja em sua versão 'científica', seja na modalidade de um ajuizamento escolar - opera, assim, como poderoso meio de realização de suas próprias profecias. Por outro lado, sua enunciação sumária e burocrática parece desonerar professores e pesquisadores da educação da busca por fatores internos às práticas escolares que sejam potencialmente condicionantes da não aprendizagem. Ao assim fazer, parecemos esquecer o fato óbvio de que “o predicado'ser reprovado' não existe a não ser pelas práticas que o produziram", como nos alerta Azanha (1995, p. 72).

Ao recusar descrições burocráticas travestidas de 'verdades científicas' e ajuizamentos preconceituosos que vinculam origem étnica e socioeconômica à incapacidade mental e à carência cultural, Souza Patto se propõe, em seu estudo, a acompanhar o cotidiano de crianças como Ângela.É a partir dessa convivência para além dos espaços marcados pelo estigma de ser uma'aluna reprovada' que se pode nela descobrir a inteligência vivaz da menina que "à noite finge que está dormindo e assiste, 'por baixo do cobertor', filmes de sexo na TV que seus pais veem porque pensam que ela está dormindo"; que se abre à possibilidade de conviver com alguém que, ao passear pelas ruas do bairro, sai a perguntar acerca de "como várias coisas que vai encontrando funcionam ou são feitas" (Pato, 2000, p. 362). Ângela deixa, assim, de ser concebida apenas a partir de dados que já sabemos de antemão - que ela é uma menina pobre, oriunda de família com pouca escolarização etc. - para ser vista como uma criança com dramas, sonhos, capacidades e limites e que, afinal, não está constitutivamente destinada ao "fracasso escolar". 
Ao contrário do cientificismo simplista e degenerado do laudo, que só pretende descrever o que Ângela é, enquadrando-a em rótulos e categorias abstratas, o que encontramos nas páginas de $A$ Produção do Fracasso Escolar é um esforço no sentido de captar quem é Ângela em sua singularidade irredutível. $E$, ao assim fazer, a concretude do cotidiano de uma escola, a saga de quatro famílias e a trajetória de quatro crianças nos fornecem elementos capazes de iluminar um conjunto de problemas e características que ainda marcam a escola pública contemporânea.

\section{Fragmentos do cotidiano e totalidade social}

As formas pelas quais temos acesso aos elementos constitutivos da cotidianidade de uma escola pública são as mais variadas e por vezes emergem de recursos pouco usuais, mas de alto poder elucidativo. Tomemos como exemplo a silenciosa eloquência da representação da escola nos desenhos de Nailton:"a escola desenhada é tão grande que quase não cabe no papel, mas a porta é pequena... Ele informa que desejava ter feito uma escada de acesso à porta, mas não pode porque não coube!" (Patto, 2000, p. 391). Sua representação gráfica (elaboração de sua experiência escolar?) é de uma construção grandiosa, mas inacessível. Não há sequer janelas e, tal como sucede com o personagem de Kafka em Diante da Lei, Nailton jamais transpõe o portão que daria acesso ao que, em tese, foi feito para lhe abrigar.

Na brincadeira de faz de conta Ângela ocupa o lugar de professora: "fica em pé, com o corpo retesado, o nariz para o alto e diz que vai 'gritar o ditado'". Repreende em voz alta a pesquisadora:"Dona Denise, para de conversar e presta atenção no ditado". A menina em seu papel de professora separa as produções em boas e ruins, entre as que merecem parabéns e a que recebem nota 4 , seguem-se às notas as medidas disciplinares:"Vai para a Diretoria, viu? E sem preguiça."Despede-se com semblante de exausta: "Os alunos dão muito trabalho, estou muito cansada, já trabaIhei muito" (Patto, 2000, p. 360), como se revelasse que o desgaste não acomete somente aos alunos.

Aprende-se, a partir dos relatos das atividades de aula, que não somente os alunos, mas as próprias professoras muitas vezes não conseguem vislumbrar um sentido para as atividades escolares ou mesmo, o que é ainda pior, para a experiência escolar como um todo.

\footnotetext{
A professora cumpre sua obrigação realizando diariamente um ritual, sempre o mesmo, destituído de vida e de significado que a mortifica; obediente mas descrente, coloca as sílabas na lousa, passa mecanicamente entre as carteiras, constata sempre os mesmos erros que aponta com maior ou menor irritação, para começar de novo no dia seguinte, no mês seguinte, no semestre seguinte. (p. 282)
} 
Essa rotina mecânica e destituída de significado formativo contamina as atividades mais elementares do cotidiano escolar. As crianças repetem as frases da lousa num ritmo maquinal: a gata mata a rata; a aranha está na sala... Mas convém não nutrir ilusões: a'técnica didática' não é a fonte da alienação do sentido formativo que uma atividade de alfabetização deveria ter, mas simplesmente um de seus efeitos mais visíveis.

\title{
Uma palavra final
}

Por décadas, na ausência de um autêntico sentido público, a escola brasileira tinha uma clara finalidade socioeconômica: operar como um mecanismo de seletividade precoce capaz de dar legitimidade social para a ideologia da meritocracia individual. Assim a experiência escolar conferia aos poucos que a ela tinham acesso uma distinção social que frequentemente se revertia em privilégio econômico. Com a expansão de seu atendimento à quase totalidade da população esvai-se seu poder de operar distinções e com ele o "sentido" (na verdade, a 'finalidade', já que era concebida mais como'meio' para um fim que lhe era extrínseco) que historicamente lhe foi associado.

A democratização de seu acesso, que poderia ter significado a ampliação de uma experiência simbólica potencialmente rica, resultou na manutenção de um "meio" para o qual já não mais se vislumbra claramente um "fim".Se já não sabemos "para que" (a finalidade) do aprendizado escolar, tampouco temos sido capazes de atribuir um "sentido" para a experiência escolar; de nela vislumbrar um significado político, cultural e formativo. É essa escola, alienada de seu papel político, divorciada de sua vocação cultural e inacessível aos pais e alunos que dela mais necessitam que encontramos nas páginas do livro de Souza Patto. Mas, ao mesmo tempo, nele encontramos os esforços de Ângela, Neide, Nailton, Humberto ou Glória para não serem tragados pela massificação, docilizados pelos processos disciplinares, assujeitados por uma máquina estatal desvinculada dos compromissos públicos que justificariam sua existência. Daí a triste, lúcida e desafiante atualidade dessa obra.

\section{The trajectory of a classic on school failure}

\begin{abstract}
Published for the first time more than two decades ago, $A$ produção do fracasso escolar, by Maria Helena Souza Patto, continues to be a reference work for researchers in education, and teachers. How can one explain its longevity and fecundity in a field that is so marked by rapid obsolescence of authors, theories and
\end{abstract}


educational perspectives? In this article, we present two complementary hypotheses for this solid trajectory of her work. The first one concerns the elucidative potential of her research that refuses the jargon and the procedures that erase the concreteness of the real in favor of a mathematized language and standardizes concepts; what, then, emerges is a complex picture of everyday life in a singular educational institution. On the other hand, in her researches the peculiarity of everyday life of an institution is not taken apart from the historical, political and social conditions which have marked the conceptions and educational practices in our society.

Keywords: School failure. Educational psychology. Teachers. Schools.

\section{La trajectoire d'un classique sur l'échec scolaire}

Résumé: Publié pour la première fois il y a plus de vingt ans, A produção do fracasso escolar, I ' oeuvre de Maria Helena Souza Patto n'a pas cessé d'être un ouvrage de référence pour les chercheurs dans l'éducation, les gestionnaires des systèmes et des enseignants. Comment expliquer sa longévité et sa fécondité dans un domaine qui est tellement marquée par une rapide obsolescence de théories et auteurs? Dans cet article, nous présentons deux hypothèses complémentaires pour cette solide trajectoire de son travail. La première concerne le potentiel $d^{\prime}$ élucidation de sa recherche que, en refusant le jargon et les concept que finissent pour effacer le concret en faveur d'un langage mathématisé et d'un ensemble de concepts padronisés, présente un important et complexe cadre de la vie quotidienne d'une institution d'enseignement et de ses agents. D'autre part, dans sa recherche la particularité de la vie quotidienne d'une institution n'est pas isolée des conditionnants politique, historique et social qui ont marqué les conceptions et les pratiques éducatives chez nous.

Mots-clés: L'échec scolaire. Psychologie de l'éducation. Enseignantes. Écoles.

\section{La trayectoria de un clásico sobre el fracaso escolar}

Resumen: Publicado por primera vez hace más de dos décadas, $A$ produção do fracasso escolar, de Maria Helena Souza Patto, sigue siendo una obra de referencia para investigadores en educación, gestores de sistemas y profesores. ¿Cómo explicar su longevidad y fecundidad en un campo tan marcado por la rápida obsolescencia de 
autores, teorías y perspectivas educacionales? En el presente artículo presentamos dos hipótesis complementarias para esa sólida trayectoria de su obra. La primera de ellas dice respeto al potencial elucidativo de su estudio que, rechazando el argot y los procedimientos cientificistas que borran la concretude del real en favor de un lenguaje matematizado y estandarizador, nos presenta un cuadro significativo y complejo de una institución escolar y de sus actores. Por otro lado, en su investigación la peculiaridad del cotidiano de una institución no se desconecta de los condicionantes históricos de naturaleza política y social que han marcado las concepciones y prácticas educativas en nuestra sociedad.

Palabras clave: Fracaso escolar. Psicología educacional. Profesores. Escuelas.

\section{Referências}

Amaral, D. K. (2010). Histórias de (re)provação escolar: vinte e cinco anos depois. Dissertação de Mestrado, Faculdade de Educação, Universidade de São Paulo, São Paulo.

Azanha, J. M. P. (1995). Educação: temas polêmicos. São Paulo: Martins Fontes.

Calvino, I. (1993). Por que ler os clássicos? São Paulo: Cia. das Letras.

Patto, M. H. S. (2000). A produção do fracasso escolar. Histórias de submissão e rebeldia. São Paulo: Casa do Psicólogo. 
José Sérgio F. de Carvalho, Docente da Faculdade de Educação da Universidade de São Paulo. Endereço para correspondência: Rua Gaicá 108, CEP: 05579-070, São Paulo, SP.Brasil.Endereço eletrônico: jsfcusp@usp.br

Recebido: $22 / 11 / 2010$

Aceito: 04/04/2011 